\title{
Proteomics study of changes in soybean lines resistant and sensitive to Phytophthora sojae
}

\author{
YuMei Zhang ${ }^{1 \dagger}$, JinMing Zhao ${ }^{1 \dagger}$, Yang Xiang ${ }^{2}$, XiaoChun Bian' , QiaoMei Zuo ${ }^{1}$, Qi Shen², JunYi Gai and Han Xing ${ }^{1 *}$
}

\begin{abstract}
Background: Phytophthora sojae causes soybean root and stem rot, resulting in an annual loss of 1-2 billion US dollars in soybean production worldwide. A proteomic technique was used to determine the effects on soybean hypocotyls of infection with $P$. sojae.

Results: In the present study, 46 differentially expressed proteins were identified in soybean hypocotyls infected with P. sojae, using two-dimensional electrophoresis and matrix-assisted laser desorption/ionization tandem time of flight (MALDI-TOF/TOF). The expression levels of 26 proteins were significantly affected at various time points in the tolerant soybean line, Yudou25, (12 up-regulated and 14 down-regulated). In contrast, in the sensitive soybean line, NG6255, only 20 proteins were significantly affected (11 up-regulated and 9 down-regulated). Among these proteins, $26 \%$ were related to energy regulation, $15 \%$ to protein destination and storage, $11 \%$ to defense against disease, $11 \%$ to metabolism, $9 \%$ to protein synthesis, $4 \%$ to secondary metabolism, and $24 \%$ were of unknown function.
\end{abstract}

Conclusion: Our study provides important information on the use of proteomic methods for studying protein regulation during plant-oomycete interactions.

\section{Background}

Soybean is one of the main sources of edible vegetable oil and high-protein livestock feed [1]. Phytophthora root and stem rot of soybeans, caused by the facultative pathogen Phytophthora sojae, is a serious disease. Each year it causes soybean damage estimated at one to two billion US dollars worldwide [2]. Breeding resistant cultivars is considered the most practical means of controlling this disease.

Two types of resistance to phytophthora root rot in soybeans have been described, partial and race-specific resistance. Partial resistance limits the spread of lesions in infected tissues. Race-specific resistance is monogenic and confers immunity or near immunity on the plant through a hypersensitive response. The different physiological pathotypes are governed by an $R p s$ gene [3,4]. Currently, only 14 Rps genes at eight loci (Rps1 to Rps8) are known to confer soybean resistance to $P$. sojae and

\footnotetext{
*Correspondence: hanx@njau.edu.cn

+ Contributed equally

${ }^{1}$ National Center for Soybean Improvement, National Key Laboratory of Crop Genetics and Germplasm Enhancement, Nanjing Agricultural University,

Nanjing 210095, P.R. China

Full list of author information is available at the end of the article
}

these have been designated and mapped to four molecular linkages: F, G, J, and N [5-8]. However, single Rps genes remain effective for 8-15 years [9]. The continuous introduction of stable Rps genes against $P$. sojae in soybean cultivars has resulted in the evolution of new pathogenic $P$. sojae races that can overcome the resistance conferred by these genes $[10,11]$. P. sojae is constantly evolving, and the number of physiological races of this oomycete pathogen is increasing rapidly [12]. Therefore, identifying and deploying new Rps genes is an essential part of soybean breeding programs.

With the development of second-generation sequencing technologies, microarray-based studies of soybean$P$. sojae interactions are becoming more common. Many candidate genes presumably involved in regulating the expression of defense-related pathways for Phytophthora resistance in soybean have been identified [13,14]. Highthroughput proteomic analysis is a powerful tool for studying changes in protein accumulation levels and posttranslational modifications [15]. In soybeans, the proteomic approach has been used to study many plantpathogen interactions, including root hair infection with Bradyrhizobium japonicum [16], soybean mosaic virus 
[17], soybean cyst nematode [18], P. sojae [19], as well as symbiotic nitrogen fixation [20], and symbiotic microbe interactions [21].

Using the hypocotyl inoculation technique, Fan et al. [22] have mapped a novel allele at the Rps1 locus, and Sun et al. [23] discovered a novel gene in Yudou25. NG6255 is sensitive after inoculation with $P$. sojae [23]. In the present study, we set out to identify $P$. sojae resistance-related proteins in the Yudou25 and NG6255 cultivars of soybean. Yudou25 and NG6255 cultivars were inoculated with $P$. sojae and the differentially expressed proteins were analyzed and compared with those found in mock-inoculated controls. The results provide insights into the molecular basis of the differential responses of these two lines to this economically important plant pathogen.

\section{Results and discussion}

Contrasting phenotypes of Yudou25 and NG6255 in terms of resistance to $P$. sojae infection

Two soybean lines were challenged with the physiological race of $P$. sojae (PNJ1) isolated at the Jiangpu Farm, Nanjing Agricultural University during the growing season of 2006 [24]. We used the race-specific hypocotyl inoculation method to evaluate the two soybean lines for resistance against $P$. sojae, and examined the effects of the pathogen on them. The appearances of the two lines 12, 24 and $48 \mathrm{~h}$ after the PNJ1 challenge are shown in Figure 1. At $12 \mathrm{~h}$ after inoculation, the sensitive line, NG6255 (Figure 1A), and the resistant line, Yudou25 (Figure 1D) showed no physical difference. However, by $24 \mathrm{~h}$ and $48 \mathrm{~h}$ after inoculation, these lines showed remarkably different symptoms. Compared with the resistant line, Yudou25 (Figures 1E, and 1F), the sensitive line, NG6255 (Figures 1B, C) exhibited large, water-soaked lesions, as well as macerated and collapsed tissues. Magnified views of NG6255 and Yudou25, at 24 $\mathrm{h}$ and $48 \mathrm{~h}$ after inoculation, are shown in Figures 1G, $\mathrm{H}$, I and $1 \mathrm{~J}$. Figures $1 \mathrm{C}$ and $1 \mathrm{H}$, show serious wilting of the leaves and noticeable maceration of the stem of NG6255 $48 \mathrm{~h}$ after inoculation with P. sojae, while Yudou25 showed only slight water-soaked lesions, indicating its higher tolerance to $P$. sojae.

\section{Proteomic patterns with and without $P$. sojae infection} Changes in the protein profiles of the hypocotyls infected with PNJ1 in the resistant line, Yudou25 (12, 24 , and $48 \mathrm{~h}$ after inoculation), and the sensitive line, NG6255 (12 and 24 h after inoculation), were examined, using a 2-dimensional electrophoretic (2-DE) analysis of the total proteins present. We used immobilized $\mathrm{pH}$ gradient (IPG) strips $(17 \mathrm{~cm}, \mathrm{pH} 4-7)$ with relative molecular masses of 14-116 kDa and a silver stain. For each sample, the gel experiments were performed at least three times, and showed a high level of reproducibility (Figures 2 and 3 for Yudou25 and NG6255, respectively). The arrows and numbers in the figures refer to spots exhibiting significant changes in relative intensity after pathogen challenge. Typically, about 1,200 protein spots were detected on each silver-stained gel using PDQuest 7.1 software.

A total of 51 spots were observed in the two lines showing $>2$-fold variation $(P<0.05)$, compared with the control at the same time point. However, five spots could not be identified. In the resistant line, 12 (spots 1, 4, 6, 7, 9, 10, 12, 16, 17, 21, 22, and 24) of the 26 spots were categorized as up-regulated, and 14 (spots 2, 3, 5, 8, 11, 13, 14, 15, 18, 19, 20, 23, 25, and 26) were down-regulated. Of these, a total of seven protein spots (spot 3, 5, 11, 13, 16, 19 and 20) showed a 2 -fold change in at least two time points. Meanwhile, in the sensitive line, 11 (spots 29, 31, 32, 33, $34,35,36,37,44,45$, and 46) were up-regulated and nine (spots 27, 28, 30, 38, 39, 40, 41, 42 and 43) were down-regulated. Meanwhile, spots 28, 34, 37, 38, 43, 44 and 45 changed significantly 12 and $24 \mathrm{~h}$ after challenge with $P$. sojae.

In general, for most of the identified proteins, the experimental molecular weight $(\mathrm{Mr})$ and isoelectric point (pI) were in reasonable agreement with the theoretical values of the matched proteins (see Additional file 1 and 2). However, differences between the experimental and theoretical values of $\mathrm{Mr}$ and $\mathrm{pI}$ for identities were also noticeable (see Additional file 1 and 2). For methionine synthase (spot 18), ribulose-1,5-bisphosphate carboxylase/oxygenase large subunit (spots 5, 15 and 26), the experimental Mr was markedly lower than the theoretical value (see Additional file 1). For phosphoglycerate kinase precursor-like protein (spot 8), ribulose1,5-bisphosphate carboxylase small subunit (spot 25) and glyceraldehyde-3-phosphate dehydrogenase A subunit (spot 33), the theoretical pIs $(7.68,8.87$ and 8.42, respectively) were beyond the $\mathrm{pH}$ range of the strips used. Wan and Liu [25] reported that the apparent $\mathrm{Mr}$ values predicted by sodium dodecyl sulfate-polyacrylamide gel electrophoresis (SDS-PAGE) had an error deviation of about $\pm 10 \%$ compared with the theoretical values. However, this phenomenon suggests that these proteins might be the partially degraded products of their intact proteins. Wan and Liu [25] also found that the observed molecular mass values of the 7 ribulose1,5-bisphosphate carboxylase/oxygenase large subunits ranged from 19.14 to $30.18 \mathrm{kDa}$. This range is much smaller than the theoretical $52.79 \mathrm{kDa}$ obtained by comparative proteomics using hydrogen peroxide stress tests in rice seedling leaves. Similar results were found in chilled rice seedling leaves, and further confirmed by Western blot analysis [26]. 


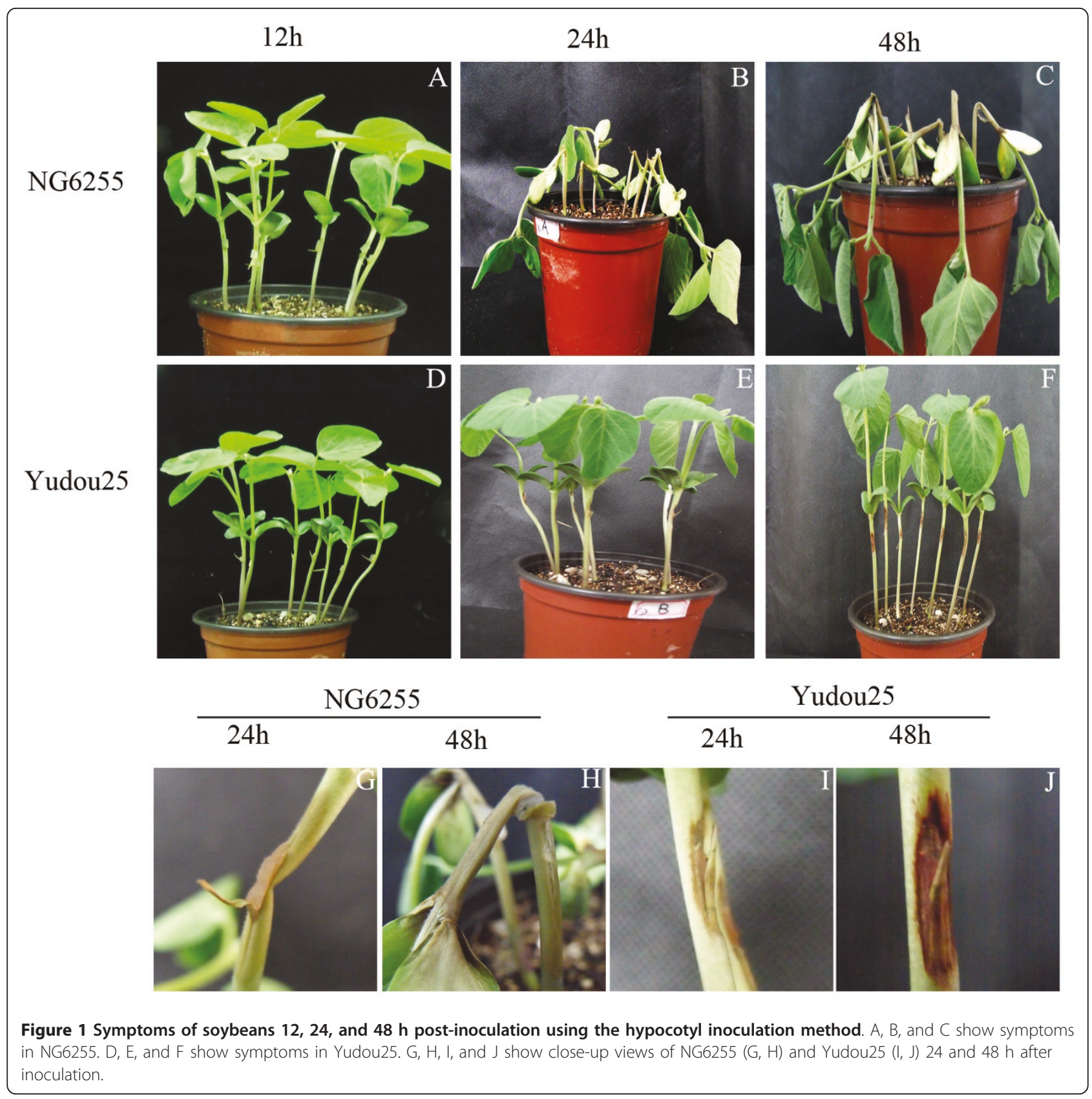

Identification and functional classification of the differentially expressed proteins by MALDI-TOF/TOF The identities of the proteins were determined using MALDI-TOF/TOF. Of the 51 proteins analyzed, 46 were identified, an identification success rate of approximately $83.8 \%$. The 46 protein spots are shown in Figure 4A (Yudou25) and 4B (NG6255).

Of these 46 spots, 35 were identified using the predicted sequences of the typical peptides from the NCBInr protein database (see Additional file 1 and 2). These 35 protein spots were placed in the current database as putative functional proteins, and the remaining
11 (spots 2, 3, 6, 16, 21, 22, 23, 29, 39, 40, and 44) were classified either as unknown or hypothetical proteins. Their identities were assigned by searching for their sequences using the BLASTP tool of the NCBInr protein database and their corresponding homologues with the highest similarity are listed in Additional file 3. All of these 11 proteins shared more than $70 \%$ positive identity with their homologues at the amino acid level, suggesting that they might have similar functions. All of the proteins identified were classified into 7 functional categories using the methods of Bevan et al. [27]: metabolism, energy, protein synthesis, protein destination 


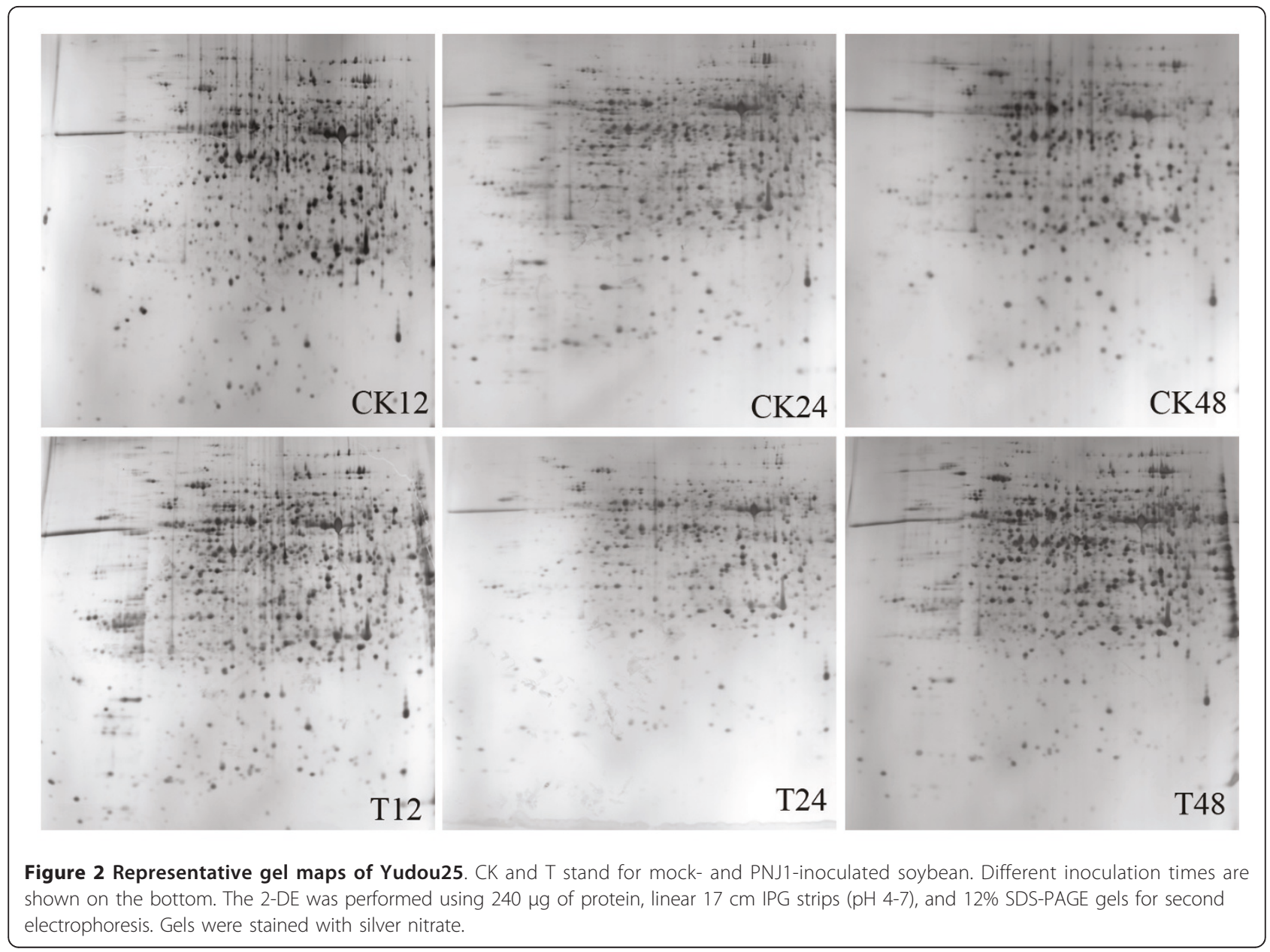

and storage, defense against disease, secondary metabolism, or unknown. Figure 5 illustrates the distribution of these functional categories in Yudou25 and NG6255. In the resistant line, Yudou25, proteins related to energy dominated $(22 \%)$. Those in the unknown, and protein destination/storage categories followed with $15 \%$ and $11 \%$, respectively. In contrast, no category predominated in the sensitive line, NG6255. Proteins involved in metabolism, defense against disease and unknown each accounted for $9 \%$ of the total. The protein group related to synthesis followed, and the group related to secondary metabolism came last.

\section{Proteins involved in metabolism and energy regulation}

Proteins involved in metabolism are essential for cell growth and maintenance. They accounted for $11 \%$ of the identified proteins in the present study. Pathogenic infections often affect certain common physiological processes, most importantly those to do with metabolism. In the present study, a number of the proteins affected at various times after pathogen challenge were those associated with energy pathways. These proteins accounted for $26 \%$ of all identified proteins, and were dominated by enzymes for glycolysis and photosynthesis.

In the resistant line, methionine synthase (spot 18) is involved in amino acid metabolism. The glycolysisrelated proteins were phosphoglycerate kinase precursor-like protein (spot 8), aldose reductase (spot 9), glyceraldehyde-3-dehydrogenase C subunit (spot 14), and triosephosphate isomerase (spot 17). The proteins involved in photosynthesis were ribulose 1,5-bisphosphate carboxylase/oxygenase (spots 5, 11, 15, and 26), ribulose 1,5-bisphosphate carboxylase small subunit (spot 25), and $\mathrm{NADP}^{+}$-malic enzyme 1 (spot 12 ).

In the resistant line, the expression levels of the proteins involved in photosynthesis were down-regulated (see Additional file 1). Similar results were observed in pea plants (cv. Alaska) infected with plum pox virus (PPV, Sharka) [28]. Most of the changes in protein expression at the sub-cellular level produced by PPV infection were related to photosynthesis and carbohydrate metabolism.

Among the identified proteins, aldose reductase (spot 9) belongs to a superfamily of soluble $\operatorname{NAD}(\mathrm{P})(\mathrm{H})$ 


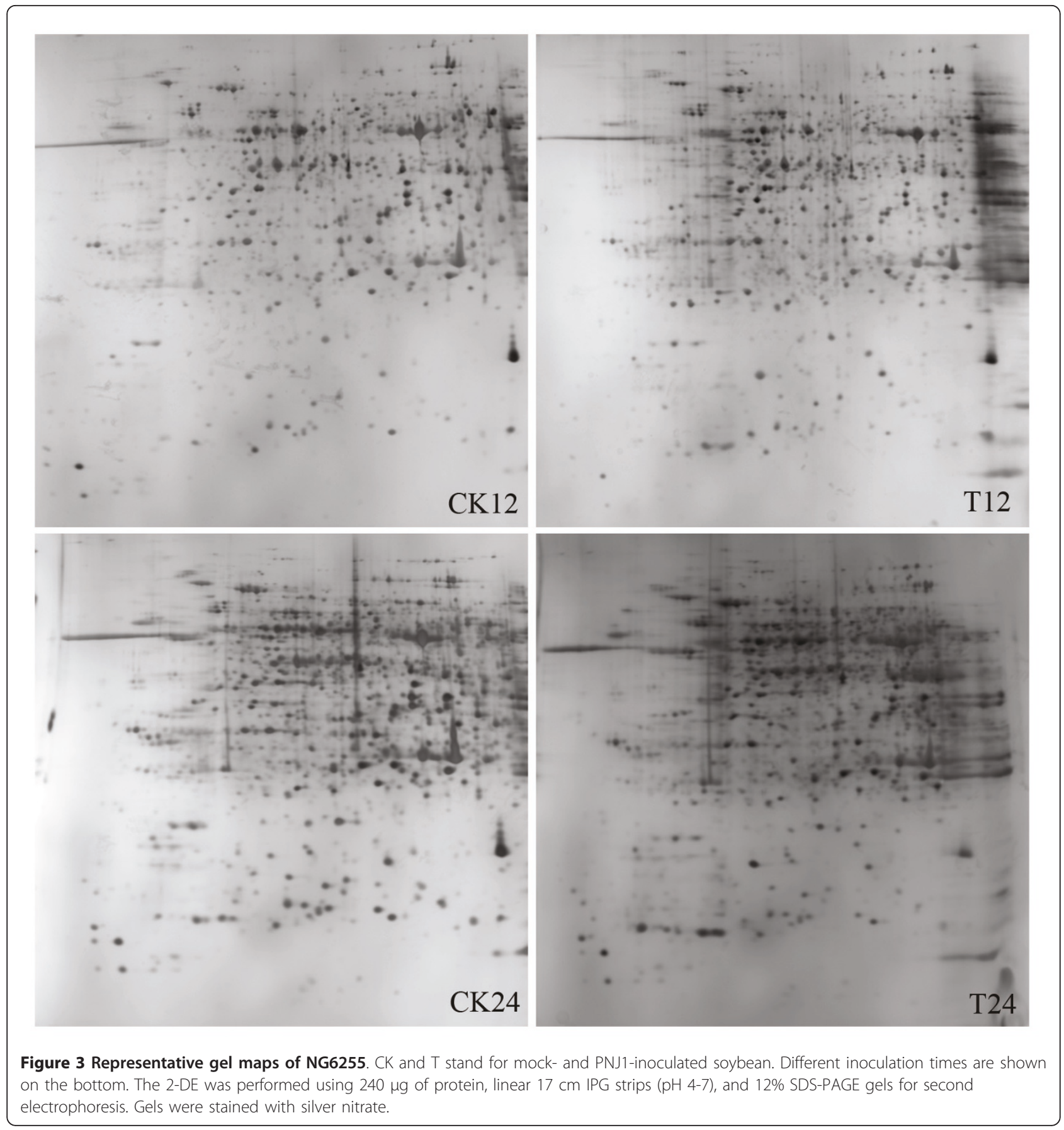

oxidoreductases. The superfamily reduces aldehydes and ketones, as well as producing ATP to protect seedlings. $\mathrm{NADP}^{+}$-Malic enzymes (spot 12 ) catalyze the oxidative decarboxylation of L-malate, producing pyruvate, $\mathrm{CO}_{2}$, and $\mathrm{NAD}(\mathrm{P}) \mathrm{H}$ in the presence of a divalent cation [29]. Spot 14 was additionally identified as GAPDH.

In the sensitive line, amino acid metabolism-related proteins included nitrite reductase (spot 28), glutamate1-semialdehyde 2,1-aminomutase (spot 31), $S$ - adenosylmethionine synthetase (spot 32), and isopropylmalate synthase (spot 42). The glycolysis-related proteins were hypothetical protein ARALYDRAFT_491252 (spot 30), and glyceraldehyde-3-dehydrogenase A subunit (spot 33).

S-Adenosylmethionine synthetase (spot 32) catalyzes the formation of $S$-adenosyl-Met from Met and ATP. Aside from its well-known role as a methyl donor in a myriad of transmethylation reactions, Ado-Met is 

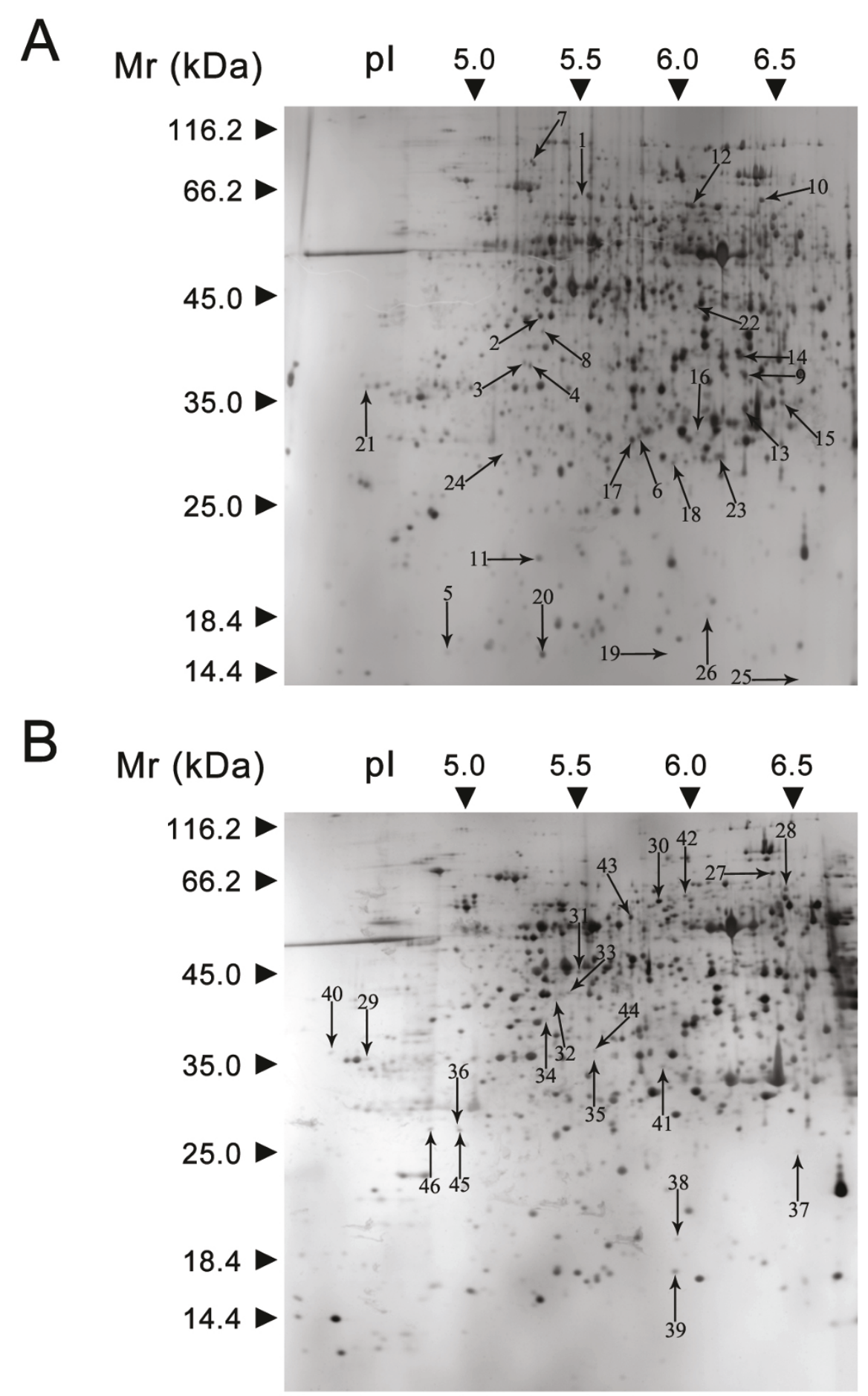

Figure 4 Identification of 26 and 20 protein spots from Yudou25 (A) and NG6255 (B), respectively. The numbers with arrows indicate the differentially expressed protein spots. pl and Mr are shown on the gels.

involved in several essential functions for plant growth and development. These include being a precursor in ethylene biosynthesis, the propylamino group donor in the biosynthesis of the polyamines spermidine and spermine, and a key enzyme in lignin biosynthesis [30]. Spot 28 (nitrite reductase) was shown to be expressed at lower levels $12 \mathrm{~h}$ after inoculation in the sensitive line. Nitrate and nitrite reductase also utilize nitrite as a 


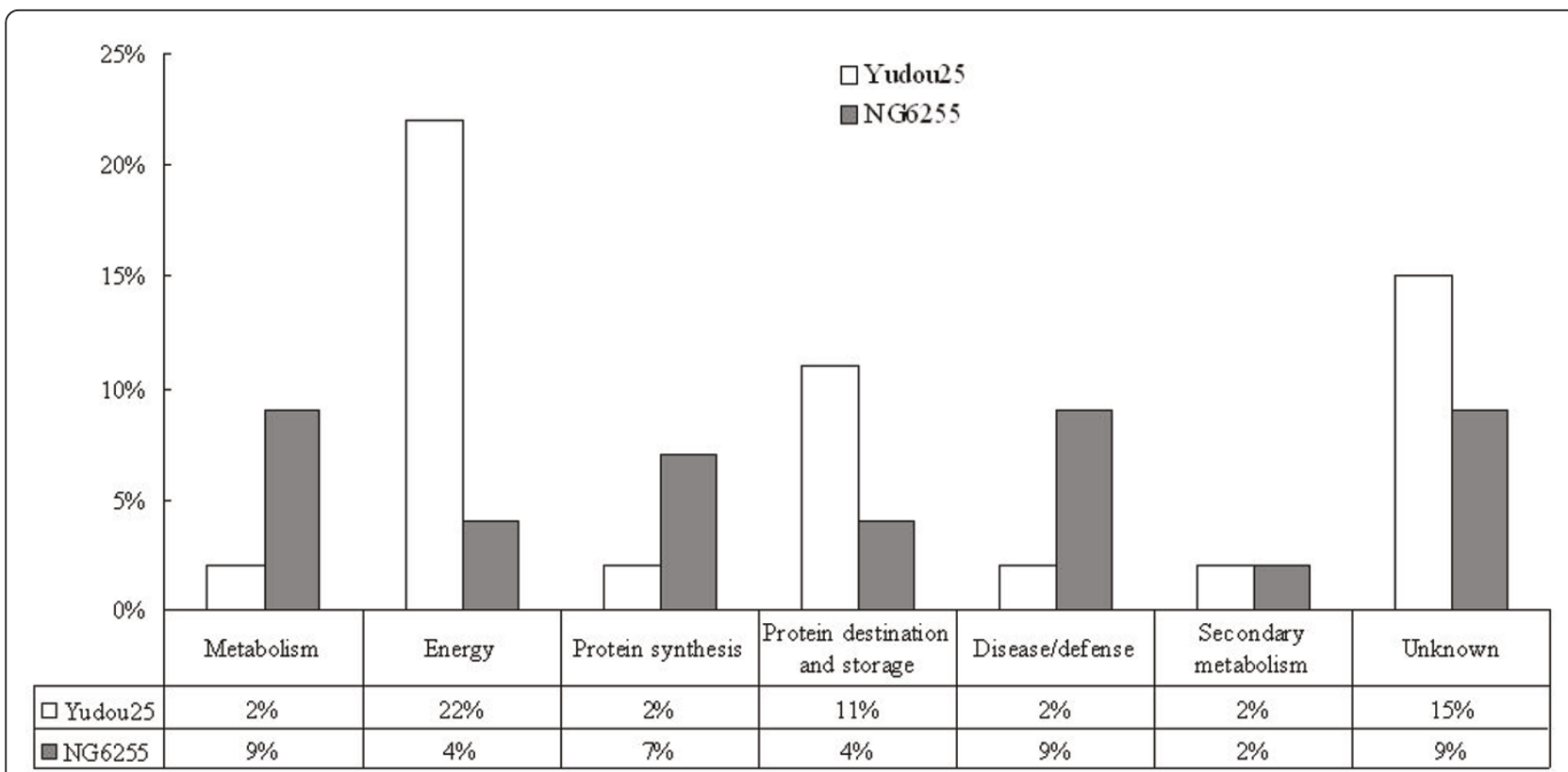

Figure 5 Distribution of identified protein classes in Yudou25 and NG6255 using the methods of Bevan et al. [27]. The percentages of the same functional class accounting for all the identified proteins from Yudou25 and NG6255 are represented in white and black, respectively.

substrate. Nitric oxide (NO) is known to play a role in promoting programmed cell death (PCD) as a means of inhibiting pathogen attack. NO can act either as an antioxidant or promote PCD, depending on its concentration, and possibly on the timing as well as location of its production [31-33].

GAPDH was identified in both resistant and sensitive lines. In general, GAPDH is considered to be a housekeeping protein involved in basic catabolic cell processes and in numerous sub-cellular metabolic processes, including gene transcription, DNA replication, and endocytosis, among others. A previous study revealed that GAPDH activity is inhibited by $\mathrm{H}_{2} \mathrm{O}_{2}$ at the proteomic level. This finding suggests that GAPDH is a direct target of $\mathrm{H}_{2} \mathrm{O}_{2}$ and may have a role in mediating the signals of reactive oxygen species (ROS) in plants [34].

For example, when rice seedlings were exposed to high doses of $\mathrm{H}_{2} \mathrm{O}_{2}$, the small exogenous, stable, $\mathrm{H}_{2} \mathrm{O}_{2}$ molecule diffused into cells by cross-membrane-bound transport [35]. Some enzymes such as membrane-bound $\mathrm{NADPH}$ oxidase and apoplast-located amine oxidase were also activate to amplify endogenous $\mathrm{H}_{2} \mathrm{O}_{2}$ [36] and the intracellular $\mathrm{H}_{2} \mathrm{O}_{2}$ level in the rice leaves increased. Excessive $\mathrm{H}_{2} \mathrm{O}_{2}$ levels in the leaves caused an imbalance of the original redox homeostasis and elevated the oxidative intensity. This phenomenon leads to changes in the biomolecular metabolism.

Based on these results, we hypothesize that in soybean-P. sojae interaction, the host limits the spread of lesions in infected tissues mainly by mediating ROS signals and initiating PCD to ward off, or antagonize, the pathogen attack.

\section{Proteins involved in defense against disease}

Overproduction of ROS is one of the first responses of plant cells to infection. ROS can also contribute to PCD, thereby serving as signal molecules for inducing local and systemic resistance [37]. Several proteins involved in detoxifying the free radicals generated during stress (e.g., pathogen challenge) were elevated after the $P$. sojae-resistant and P. sojae-sensitive lines were challenged with the pathogen.

In the resistant line, the proteins related to defense against disease were ascorbate peroxidase (spot 24). In the sensitive line, these proteins were ascorbate peroxidase (APx, spots 45, and 46), cytosolic ascorbate peroxidase 2 (spot 36) and lectin (spot 41).

Lectin (spot 41) was down-regulated in the sensitive line. Most plant lectins play a role in defending against different kinds of attacking organisms [38,39]. Galectins are released from outer membranes by enzymatic digestion of surface carbohydrates [40]. Soluble plant lectins are also possibly linked to a region near the plasma membrane through interactions with surface glycoproteins. The secretion of plant lectins into the medium may play a role in defense or symbiosis via bacterial or fungal binding and subsequent agglutination. Similar results are shown in proteome analysis to flood stress [41] and $\mathrm{NaCl}$ stress [42] in soybean roots and hypocotyls. 
APXs, components of the ascorbate-glutathione cycle are widely distributed in plant cytosol, mitochondria, chloroplasts and other cellular compartments [33,43]. In these organelles, ROS scavenging is required because of the importance of the ascorbate-glutathione cycle in maintaining cellular ROS homeostasis. The elevated levels of ascorbate peroxidase observed in this study possibly led to an amelioration of infection-induced oxidative stress. The intensities of the spots identified as APx increase in both resistant and sensitive lines, suggesting that differences in antioxidant responses may have important roles in determining the outcome of an infection. The role of APx in defence against P. sojae needs further study.

\section{Proteins involved in protein synthesis, destination, and storage}

A total of 11 identified proteins (24\%) that responsed to $P$. sojae infection (see Additional file 1 and 2) were divided into two functional groups. The first group consisted of four proteins active in protein synthesis, and the second comprised seven proteins related to destination and storage.

In the resistant line, the proteins active in synthesis, and protein destination and storage (spot 7, translation elongation factor EF-G) accounted for $2 \%$ and $13 \%$ of the total, respectively.

In the sensitive line, those involved in protein synthesis (7\%) were 60S acidic ribosomal protein P0 (spot 34), hypothetical protein SORBIDRAFT_0525s002010 (spot 35), and eukaryotic translation initiation 5A-2 (spot 38). Those related to protein destination and storage (4\%) were HSP STI (spot 27) and $31 \mathrm{kDa}$ glycoprotein (spots 37 ).

HSPs are responsible for protein refolding and assembly, thereby conferring protection. HSPs are active in diverse cellular processes as molecular chaperones [44]. The intensity of HSP70 (spot 1) and LOC100285569 (spot 10) were up-regulated after challenge in the resistant line. In contrast, HSP STI (spot 27) was down-regulated in the sensitive line. Some proteins involved in synthesis were up-regulated, but others with similar functions, were down-regulated. These results suggested that these proteins had different regulatory pathways.

The $31 \mathrm{kDa}$ glycoproteins (spots 13, 19, 20) in the resistant line were down-regulated, but up-regulated in the sensitive line (spot 37 ). The stem $31 \mathrm{kDa}$ glycoprotein precursor may function as a somatic storage protein during early seedling development, and accumulates mainly in the stems of developing soybean seedlings $[45,46]$. Similar results occur in proteome analysis of soybean leaves, hypocotyls and roots under salt stress $[42,47]$ and flood stress [41].

\section{Proteins involved in secondary metabolism}

Secondary metabolites are distinct from the components of intermediary (primary) metabolism in that they are not generally essential for the basic metabolic processes of the plant. However, they do play a crucial role in many plant processes, and their syntheses should be intensified during pathogen infection. Important compounds such as lignin, suberin, cell wall-bound phenolics, and flavonoids derive their building units from the phenylpropanoid pathway. These compounds are essential in defense and tissue reconstruction [48-50].

Spot 4 was identified as thiamin biosynthetic enzyme in the resistant line Yudou25. This protein was up-regulated at $48 \mathrm{~h}$ after pathogen challenge.

A recent study suggested that thiamin can directly act as an antioxidant [51]. The association between thiamin-dependent enzymes and oxidative stress may also indicate the activity of several cofactors for thiamin under stress conditions. Ahn et al. [52,53] reported that thiamin treatment induced systemic acquired resistance in plants. Meanwhile, the exogenous application of thiamin has been shown to counteract the harmful effects of salinity on growth [54], as well as to confer resistance to fungal, bacterial, and viral infections in rice (Oryza sativa), Arabidopsis, and certain vegetable crop species [55]. The role of thiamin biosynthetic enzymes in mediating the response to $P$. sojae warrants further investigation.

Spot 43 was also involved in secondary metabolism in the sensitive line. Myo-inositol-1-phosphate synthase (MIPS) catalyzes the conversion of D-glucose 6-phosphate to 1-L-myo-inositol-1-phosphate. This conversion is the first, and rate-limiting step in the biosynthesis of all inositol-containing compounds, including phospholipids, either directly or by salvage [56].

Iqbal et al. [57] reported that MIPS plays an important role in initiating and/or maintaining the defense response of soybean to $F$. solani infection, via $\mathrm{Ca}^{2+}$ signaling. MIPS1 has a significant impact on myo-inositol levels that is critical for maintaining levels of ascorbic acid, phosphatidylinositol, and ceramides. These compounds regulate growth, development, and cell death in A. thaliana [58]. Other studies have shown that introgression of PcINO1 gene from Porteresia coarctata (Roxb.) Tateoka, confers salt tolerance on transgenic tobacco plants. This gene codes a novel salt-tolerant, Lmyo-inositol 1-phosphate synthase (MIPS) protein $[59,60]$. In our study, the intensity of MIPS was similarly down-regulated, which suggested its vital role in P. sojae infection.

\section{Proteins of unknown identity}

Eleven of the proteins isolated (24\% of the total) were classified as unknown, including seven (15\%) in the 
resistant line, Yudou25, and four (9\%) in the sensitive line, NG6255. Their homologues based on the NCBI database by BLASTP are shown in Additional file 3, and the homologues with the highest homology are also shown in Additional file 3.

The homologues of the unknown $P$. sojae responsive proteins were found to be involved in diverse biological processes, from signal transduction (spots 2 and 16), defense against disease (spots 3 and 39), metabolism and energy regulation (spots 6, 23 and 44), protein synthesis (spots 21 and 29), protein destination and storage (spot 40) and secondary metabolism (spot 22).

Spot 2 belongs to an adenosine kinase-like protein. Spot 16 had the highest homology to indole-3-glycerol phosphate lyase (IGL2). IGL cleaves indole-3-glycerol phosphate (IGP) to form indole and glyceraldehydes-3phosphate. Indole, which is part of the cocktail, is produced by an enzyme recruited from primary metabolism, and can function either as a volatile signal or be converted by specific cytochrome P450 enzymes into benzoxazinoids, which function as important defense chemicals [61]. IGL2 is involved in auxin-mediated signal transduction. The interaction of auxin with its cellular receptors for IGL2 triggers a cascade of events resulting in response including the modification of cell wall components such as lipids, and in altering the orientation of cell wall polysaccharides [62]. In a previous study, the application of indole-3-acetic acid decreased the incidence of disease caused by the tomato pathogen Fusarium oxysporum lycopersici and increased plant-growth [63]. The proteome-level results suggested ROS-mediated auxin signaling had a role in the Brassica napus-Alternaria brassicae interaction [64].

Spot 3 and 39 were highly homologous to globulin and peroxiredoxin, respectively. These two protein spots may take part in denfense against disease. Spot 40 was identified as Nascent polypeptide-associated complex subunit alpha-like protein 2 (NACA2), which take part in correct orientation of ribosomal nascent polypeptides with directional factors. The decreasing expression of spot 40 identified from the sensitive line, NG6255, could cause inaccurate direction, or indirection, for most nascent proteins, resulting in the proteins becoming dysfunctional, or not being delivered to the right place to function properly. Spot 44 (gi|255638532) belongs to the Aldose 1-epimerase family of proteins, which are key enzymes in carbohydrate metabolism. These enzymes catalyze the inter-conversion of the $\alpha$ - and $\beta$ anomers of hexose sugars such as glucose and galactose.

Lignification processes are important in protecting plants from pathogen attack. The closest homologue to S-adenosyl-L-methionine:caffeic acid 3-o-methyltransferase (COMT) was spot 22. This transferase catalyzes the conversion of caffeic acid to ferulic acid, a key step in the biosynthesis of lignin monomers [65]. These products are the intermediates for lignin formation, and the down-regulation of this enzyme may indicate decreased cell wall lignification. Guo et al. [66] reported that strong down-regulation of COMT resulted in decreasing lignin content in transgenic alfalfa plants harboring COMT. In the present study, spot 22 was up-regulated in the resistant line, Yudou25, indicating that enhanced lignin biosynthesis may play a role in mediating the effects observed during soybean- $P$. sojae interaction, and should be further investigated.

\section{Conclusion}

Proteomic analysis has the potential to provide significant insights into the molecular events that occur during plant-pathogen interactions. In the present study, we investigated the proteome-level changes that occur during soybean-P. sojae interaction using 2-DE and tandem MS. The proteins showing two-fold changes in intensities are related to biochemical processes that may be differentially altered at various time points after pathogen challenge. Whereas some enzymes/proteins are involved in glycolysis and photosynthesis, others are involved in protein synthesis, destination and storage, defense against disease, as well as in secondary metabolism. The results from the present study offer insights into the repertoire of mechanisms used by $P$. sojae during its infection and colonization of a host.

\section{Methods}

\section{$P$. sojae isolate and plant material}

PNJ1 was originally isolated from the diseased tissues of soybean and soil samples in Nanjing in 2006 [24]. The isolate was established from single oospores, and was tested for virulence pathotype using the hypocotyl inoculation method on 14 differential cultivars. The virulence formula of PNJ1 is $1 \mathrm{~d}, 2,3 \mathrm{~b}, 3 \mathrm{c}, 4,6,7$. The isolate was maintained on V8-juice agar plates, in the dark, at $25^{\circ} \mathrm{C}$.

The plant materials used included cultivars Yudou25 and NG6255, previously screened from Huanghuai valley cultivars via the hypocotyl inoculation technique [67]. Yudou25 is a PNJ1-resistant cultivar, whereas NG6255 is sensitive to PNJ1 [23]. Their seedlings were grown on a commercially available 3:1 mixture of vermiculite and peat moss, under controlled conditions (16 h light, $8 \mathrm{~h}$ dark; $28{ }^{\circ} \mathrm{C}$ at day, $22{ }^{\circ} \mathrm{C}$ at night; $60 \%$ relative humidity; light intensity $600 \mu \mathrm{mol}$ photons $\mathrm{m}^{-2} \mathrm{~s}^{-1}$ ).

The soybean lines were evaluated using the hypocotyl inoculation method [68] with minor modifications. Mycelia from 7-day-old V8 cultures were inoculated into an incision in the hypocotyls of the seedlings when the cotyledons were fully opened. The seedlings were then placed in a mist chamber ( $90 \%$ relative humidity) 
at $25{ }^{\circ} \mathrm{C}$ with a $16: 8 \mathrm{~h}$ light:dark cycle. The control plants were wounded but not inoculated with the mycelia. The hypocotyl section samples were collected from $10 \mathrm{~mm}$ below and above the incision after inoculation.

\section{Protein sample preparation}

Soybean stem proteins were extracted using a modified trichloroacetic acid/acetone procedure following Natarajan et al. [69], with minor modifications. The precipitated proteins were washed with ice-cold acetone containing $10 \mathrm{mM}$ dithiothreitol (DTT) and $1 \mathrm{mM}$ phenylmethanesulfonyl fluoride to remove pigments and lipids until the supernatant was colorless. The pellet was vacuum dried, resuspended in resolubilization solution \{7 M urea, $2 \mathrm{M}$ thiourea, 4\% [(3-cholamidopropyl) dimethylammonio] propanesulfonic acid (CHAPS), 50 mM DTT, 0.5\% Bio-Lyte 4/7 ampholyte\}, and sonicated to extract the proteins. After incubation at $25{ }^{\circ} \mathrm{C}$ for 4 $h$, the suspension was centrifuged at $15,000 \times g$ for 30 min at $4{ }^{\circ} \mathrm{C}$ to remove the insoluble material. The protein concentration of the final supernatant was measured following Bradford [70], using bovine serum albumin as the standard.

\section{2-DE, gel staining, and image analysis}

One-DE was performed in a Bio-Rad PROTEAN IEF Cell. The protein extract was diluted to a final concentration of $800 \mu \mathrm{g} / \mathrm{ml}$ with an IEF rehydration solution [7 M urea, $2 \mathrm{M}$ thiourea, 4\% CHAPS $(w / v)$, $50 \mathrm{mM}$ DTT, and $0.5 \%(v / v)$ IPG buffer ( $\mathrm{pH} 4-7)$ ]. After centrifugation for $15 \mathrm{~min}$ at $10,000 \times g, 300 \mu \mathrm{l}$ of supernatant was loaded onto a commercially available precast IPG strip with a linear $17 \mathrm{~cm} \mathrm{pH} \mathrm{4-7} \mathrm{gradient} \mathrm{and} \mathrm{then} \mathrm{actively}$ rehydrated at $50 \mathrm{~V}$ for $13 \mathrm{~h}$ at $20^{\circ} \mathrm{C}$. Focusing was performed on a Bio-Rad PROTEAN IEF Cell under the following conditions: $100 \mathrm{~V}$ for $1 \mathrm{~h}, 500 \mathrm{~V}$ for $1 \mathrm{~h}, 1000 \mathrm{~V}$ for $2 \mathrm{~h}, 8000 \mathrm{~V}$ for $4 \mathrm{~h}$, and then $8000 \mathrm{~V}$ for $7.5 \mathrm{~h}$. Approximately 60,000 Vh was achieved. Before SDSPAGE, the strips were equilibrated for $15 \mathrm{~min}$ in $10 \mathrm{ml}$ of a reducing equilibration buffer [ $6 \mathrm{M}$ urea, $0.375 \mathrm{M}$ Tris- $\mathrm{HCl}(\mathrm{pH} 8.8), 2 \%(w / v)$ SDS, $20 \%$ glycerol $(v / v)$, and $2 \%(w / v)$ DTT]. The strips were subsequently placed for another $15 \mathrm{~min}$ in alkylating equilibration buffer containing $2.5 \%(\mathrm{w} / \mathrm{v})$ iodoacetamide instead of 2\% DTT.

The second dimension was run on a $12 \%$ polyacrylamide SDS gel using an EttanTM DALT SIX System (GE Healthcare). The electrophoresis was carried at $20{ }^{\circ} \mathrm{C}$ and $1.0 \mathrm{~W} /$ gel for $40 \mathrm{~min}$ and then at $10 \mathrm{~W} /$ gel until the dye front reached about $1 \mathrm{~cm}$ from the bottom of the gel.

The gels were stained with silver nitrate as described by Yan et al. [71]. The silver-stained 2-DE gels were digitized with a Versdoc 3000 scanner (Bio-Rad), and analyzed using PDQuest software (version 7.1, Bio-Rad, Hercules, CA, USA). The images were properly cropped and optimized before performing the gel-to-gel matching of the standard protein maps. Before spot matching, one of the gel images was selected as a reference gel. The spot detection parameters were optimized by checking different protein spots in certain regions of the gel, which were then automatically detected. Visual inspection followed to remove or add undetected spots. Spot detection was refined by a manual spot edition where needed. The amount of a protein spot was expressed as the volume of that spot, defined as the sum of the intensities of all the pixels that make up the spot. To correct the variability due to the loading and gel staining, as well as to reflect the quantitative changes in the intensity of the protein spots, the spot volumes were normalized as a percentage of the total volume of all the spots in the gel. The resulting data from the image analyses were transferred to PDQuest software for querying protein spots that showed quantitative and qualitative variations. Triplicate gels were used for each sample. Only those changes that were reproducible and showed at least two-fold increase/decrease, as well as being statistically significant (using Student's $t$-test, at $P$ $<0.05$ ) were considered to be differentially expressed protein spots.

\section{In-gel digestion, mass spectrometry analysis, and database search}

Differentially expressed proteins were manually selected and excised for protein identification. The in-gel digestion of protein spots was carried out following Gharahdaghi et al. [72]. The samples were analyzed with a 4800 MALDI-TOF/TOF Proteomics Analyzer (Applied Biosystems, USA). A combined search (MS plus MS/MS) were performed using GPS Explorert ${ }^{\mathrm{TM}}$ software (version 3.5, Applied Biosystems, USA). The TOF spectra were recorded in positive ion reflector mode with a mass range from 800 to $4000 \mathrm{Da}$. About eight subspectra with 60 shots per subspectrum were accumulated to generate one main TOF spectrum. Data were searched on the Internet using a Mascot search engine (Matrix Science, Ltd., London, UK) against all entries in the NCBInr database (version 841369 sequences). Viridiplantae (Green Plants) was selected as the taxonomic category. All peptide masses were assumed monoisotopic and $[\mathrm{M}+\mathrm{H}]^{+}$. The other parameters used for the search were: enzyme of trypsin; one missed cleavage site at most; fixed modifications of cysteines carbamidomethylation and variable modifications of methionine oxidation; peptide tolerance within $50 \mathrm{ppm}$, and MS/MS tolerance of $0.2 \mathrm{Da}$. The confidence in the peptide mass fingerprinting matches $(P<0.05)$ was based on the MOWSE score and confirmed by the accurate 
overlapping of the matched peptides with the major peaks of the mass spectrum. Only significant hits, as defined by a MASCOT probability analysis $(P<0.05)$, were accepted.

\section{Additional material}

Additional file 1: Identification of 26 proteins from the resistant line Yudou 25 at various times after challenge with the pathogen. a) Spot No, Spot number; b)Names and species of proteins obtained via the MASCOT software from the NCBInr database; c) Accession No, Accession number; d)The sequences of all the identified peptides with the corresponding ion score in brackets that were matched based on the MS/MS patterns; e)MOWSE score probability (protein score) for the entire protein and for ions complemented by the percentage of the confidence index (C.I.); f)SC, Sequence coverage; g)MP/UMP indicate the number of matched and unmatched peaks for the PMF data, respectively; h) Theor. Mr/pl shows theoretical molecular weight and $\mathrm{pH}$ isoelectric; i)Exp. Mr/pl shows experimental molecular weight and isoelectric point; j)Fold change was calculated from pathogen-challenged tissue over the control gels, which '-' stands for down-regulated.

Additional file 2: Identification of $\mathbf{2 0}$ proteins from the sensitive line NG6255 at various times after challenge with the pathogen. a) Spot No, Spot number; b)Names and species of proteins obtained via the MASCOT software from the NCBInr database; c) Accession No, Accession number; d)The sequences of all the identified peptides with the corresponding ion score in brackets that were matched based on the MS/MS patterns; e)MOWSE score probability (protein score) for the entire protein and for ions complemented by the percentage of the confidence index (C.I.); f)SC, Sequence coverage; g)MP/UMP indicate the number of matched and unmatched peaks for the PMF data, respectively; h) Theor. Mr/pl shows theoretical molecular weight and $\mathrm{pH}$ isoelectric; i)Exp. Mr/pl shows experimental molecular weight and isoelectric point; j)Fold change was calculated from pathogen-challenged tissue over the control gels, which '-' stands for down-regulated.

Additional file 3: The corresponding homologues of the eleven unknown proteins. BLASTP(NCBI) was used to search the homologues of the unknowm proteins in additional file 1 and 2. The homologues with the highest homology are shown. a) The accession number of the unknown proteins in additional file 1 and $2 ; b$ ) The accession number of the homologues; c) The extent to which two amino acid sequences are invariant; d) The similarities based on the scoring matrix used.

\section{Acknowledgements}

The authors are grateful to Prof. YC Wang (Nanjing Agricultural University) for providing the isolates of $P$. Sojae. This research was mainly supported by Research Fund for the Doctoral Program of Higher Education of China (NO:20090097120023), the special program of Agricultural Ministry of China (nyhyzx07-053) and the Program for Changjiang Scholars and Innovative Research Team in University (PCSIRT).

\section{Author details}

${ }^{1}$ National Center for Soybean Improvement, National Key Laboratory of Crop Genetics and Germplasm Enhancement, Nanjing Agricultural University, Nanjing 210095, P.R. China. ' Guizhou Rapeseed Institute, Guizhou Academy of Agricultural Sciences, Guiyang 550008, P.R.China.

\section{Authors' contributions}

BXC and ZQM carried out sample collection and protein extraction, ZYM and ZJM carried out 2-DE, image acquisition and data analysis. XY and SQ helped in manuscript revision. GJY and XH conceived, designed and implemented this study. All authors read and approved the final manuscript.

\section{Competing interests}

The authors declare that they have no competing interests.
Received: 1 March 2011 Accepted: 7 September 2011

Published: 7 September 2011

\section{References}

1. Luo Q, Yu B, Liu Y: Differential sensitivity to chloride and sodium ions in seedlings of Glycine max and $\mathrm{G}$. soja under $\mathrm{NaCl}$ stress. Journal of plant physiology 2005, 162:1003-1012.

2. Tyler B: Phytophthora sojae: root rot pathogen of soybean and model oomycete. Molecular plant pathology 2007, 8:1-8.

3. Gao H, Narayanan NN, Ellison L, Bhattacharyya MK: Two classes of highly similar coiled coil-nucleotide binding-leucine rich repeat genes isolated from the Rps1-k locus encode Phytophthora resistance in soybean. Mol Plant Microbe Interact 2005, 18:1035-1045.

4. Gordon S, St Martin S, Dorrance A: Rps8 maps to a resistance gene rich region on soybean molecular linkage group F. Crop science 2006, 46:168-173.

5. Burnham K, Dorrance A, VanToai T, St Martin S: Quantitative Trait Loci for Partial Resistance to Phytophthora sojae in Soybean. Crop science 2003, 43:1610-1617.

6. Demirbas A, Rector B, Lohnes D, Fioritto R, Graef G, Cregan P, Shoemaker R, Specht J: Simple sequence repeat markers linked to the soybean Rps genes for phytophthora resistance. Crop science 2001, 41:1220-1227.

7. Diers B, Mansur L, Imsande J, Shoemaker R: Mapping Phytophthora resistance loci in soybean with restriction fragment length polymorphism markers. Crop science 1992, 32:377-383.

8. Weng C, Yu K, Anderson T, Poysa V: Mapping genes conferring resistance to Phytophthora root rot of soybean, Rps1a and Rps7. Journal of Heredity 2001, 92:442-446.

9. Schmitthenner A: Problems and progress in control of Phytophthora root rot of soybean. Plant disease 1985, 69:362-368.

10. Dorrance A, McClure S, St. Martin S: Effect of partial resistance on Phytophthora stem rot incidence and yield of soybean in Ohio. Plant disease 2003, 87:308-312.

11. Grau CR, Dorrance AE, Bond J, Russin J: Fungal diseases. In Soybeans: Improvement, Production, and Uses. Volume 16. 3 edition. Edited by: Boerma HR, Specht JE. Agronomy Monograph. American Society of Agronomy, Crop Science Society of America, Soil Science Society of America, Madison, WI; 2004:689-697.

12. Leitz R, Hartman G, Pedersen W, Nickell C: Races of Phytophthora sojae on soybean in Illinois. Plant disease 2000, 84:487-487.

13. Moy P, Qutob D, Chapman B, Atkinson I, Gijzen M: Patterns of gene expression upon infection of soybean plants by Phytophthora sojae. Molecular Plant-Microbe Interactions 2004, 17:1051-1062

14. Narayanan NN, Grosic S, Tasma I, Grant D, Shoemaker R, Bhattacharyya MK: Identification of candidate signaling genes including regulators of chromosome condensation 1 protein family differentially expressed in the soybean"CPhytophthora sojae interaction. TAG Theoretical and Applied Genetics 2009, 118:399-412.

15. Campo S, Carrascal M, Coca M, Abián J, San Segundo B: The defense response of germinating maize embryos against fungal infection: a proteomics approach. Proteomics 2004, 4:383-396.

16. Wan J, Torres M, Ganapathy A, Thelen J, DaGue B, Mooney B, Xu D, Stacey G: Proteomic analysis of soybean root hairs after infection by Bradyrhizobium japonicum. Molecular Plant-Microbe Interactions 2005, 18:458-467.

17. Yang H, Huang Y, Zhi H, Yu D: Proteomics-based analysis of novel genes involved in response toward soybean mosaic virus infection. Molecular biology reports 2011, 38:511-521.

18. Afzal AJ, Natarajan A, Saini N, lqbal MJ, Geisler M, El Shemy HA, Mungur R, Willmitzer $\mathrm{L}$, Lightfoot DA: The nematode resistance allele at the rhg1 locus alters the proteome and primary metabolism of soybean roots. Plant physiology 2009, 151:1264-1280.

19. Qiu HM, Y LC, J ZD, J XX, L WJ, J W, Y SC, P SD, H HG, S CQ: Proteome Analysis of Resistance to Phytophora Root Rot in Soybean. ACTA AGRONOMICA SINICA 2009, 35:418-423.

20. El Yahyaoui F, Kuster $\mathrm{H}$, Ben Amor B, Hohnjec N, Puhler A, Becker A, Gouzy J, Vernie T, Gough C, Niebel A: Expression profiling in Medicago truncatula identifies more than 750 genes differentially expressed during nodulation, including many potential regulators of the symbiotic program. Plant physiology 2004, 136:3159-3176. 
21. Senthil S, Un-Haing C, Carol K, Oliver Y: Distinct changes in soybean xylem sap proteome in response to pathogenic and symbiotic microbe interactions. BMC Plant Biology 2009, 9:119-129.

22. Fan AY, Wang XM, Fang XP, Wu XF, Zhu ZD: Molecular Identification of Phytophthora Resistance Gene in Soybean Cultivar Yudou 25. ACTA AGRONOMICA SINICA 2009, 35:1844-1850.

23. Sun S, Wu X, Zhao J, Wang Y, Tang Q, Yu D, Gai J, Xing H: Characterization and mapping of RpsYu25, a novel resistance gene to Phytophthora sojae. Plant Breeding 2011, 130:139-143.

24. Wu XL, Zhao JM, Wang YL, Sun S, GUO N, Tang QH, Wang YC, GAI JY, Xing $\mathrm{H}$ : Identification and isolation of soybean root rot in Nanjing. Journal of Nanjing Agricultural University 2009, 32:61-64.

25. Wan $X Y$, Liu JY: Comparative proteomics analysis reveals an intimate protein network provoked by hydrogen peroxide stress in rice seedling leaves. Molecular \& Cellular Proteomics 2008, 7:1469-1488.

26. Yan SP, Zhang QY, Tang ZC, Su WA, Sun WN: Comparative proteomic analysis provides new insights into chilling stress responses in rice. Molecular \& Cellular Proteomics 2006, 5:484-496.

27. Bevan M, Bancroft I, Bent E, Love K, Goodman H, Dean C, Bergkamp R, Dirkse W, Van Staveren M, Stiekema W: Analysis of $1.9 \mathrm{Mb}$ of contiguous sequence from chromosome 4 of Arabidopsis thaliana. Nature 1998, 391:485-493.

28. Díaz-Vivancos P, Clemente-Moreno M, Rubio M, Olmos E, García J, MartínezGómez P, Hernández J: Alteration in the chloroplastic metabolism leads to ROS accumulation in pea plants in response to plum pox virus. Journal of experimental botany 2008, 59:2147-2160.

29. Chang G, Tong L: Structure and Function of Malic Enzymes, A New Class of Oxidative Decarboxylases. Biochemistry 2003, 42:12721-12733.

30. Ravanel S, Gakiére B, Job D, Douce R: The specific features of methionine biosynthesis and metabolism in plants. Proceedings of the National Academy of Sciences of the United States of America 1998, 95:7805-7812.

31. Delledonne M, Zeier J, Marocco A, Lamb C: Signal interactions between nitric oxide and reactive oxygen intermediates in the plant hypersensitive disease resistance response. Proceedings of the National Academy of Sciences 2001, 98:13454-13459.

32. Beligni MV, Fath $A$, Bethke PC, Lamattina L, Jones RL: Nitric oxide acts as an antioxidant and delays programmed cell death in barley aleurone layers. Plant physiology 2002, 129:1642-1650.

33. De Pinto MC, Paradiso A, Leonetti P, De Gara L: Hydrogen peroxide, nitric oxide and cytosolic ascorbate peroxidase at the crossroad between defence and cell death. The Plant Journal 2006, 48:784-795.

34. Yang F, Wang Y, Miao LF: Comparative physiological and proteomic responses to drought stress in two poplar species originating from different altitudes. Physiologia Plantarum 2010, 139:388-400.

35. Bienert GP, Schjoerring JK, Jahn TP: Membrane transport of hydrogen peroxide. Biochimica et Biophysica Acta (BBA)-Biomembranes 2006, 1758:994-1003.

36. Mittler R: Oxidative stress, antioxidants and stress tolerance. Trends in plant science 2002, 7:405-410

37. Corpas F, Barroso J, del Río L: Peroxisomes as a source of reactive oxygen species and nitric oxide signal molecules in plant cells. Trends in plant science 2001, 6:145-150.

38. Peumans W, Van Damme E: The role of lectins in plant defence. The Histochemical Journal 1995, 27:253-271.

39. Peumans W, Van Damme E: Lectins as plant defense proteins. Plant physiology 1995, 109:347-352

40. Garner O, Baum L: Galectin-glycan lattices regulate cell-surface glycoprotein organization and signalling. Biochemical Society transactions 2008, 36:1472-1477.

41. Komatsu S, Sugimoto T, Hoshino T, Nanjo Y, Furukawa K: Identification of flooding stress responsible cascades in root and hypocotyl of soybean using proteome analysis. Amino Acids 2010, 38:729-738.

42. Aghaei K, Ehsanpour A, Shah A, Komatsu S: Proteome analysis of soybean hypocotyl and root under salt stress. Amino Acids 2009, 36:91-98.

43. Fath $A$, Bethke $P C$, Jones RL: Enzymes that scavenge reactive oxygen species are down-regulated prior to gibberellic acid-induced programmed cell death in barley aleurone. Plant physiology 2001, 126:156-166.

44. Hong S, Vierling E: Mutants of Arabidopsis thaliana defective in the acquisition of tolerance to high temperature stress. Proceedings of the
National Academy of Sciences of the United States of America 2000, 97:4392-4397.

45. Mason HS, Guerrero FD, Boyer JS, Mullet JE: Proteins homologous to leaf glycoproteins are abundant in stems of dark-grown soybean seedlings. Analysis of proteins and cDNAs. Plant molecular biology 1988, 11:845-856.

46. Staswick PE: Soybean vegetative storage protein structure and gene expression. Plant physiology 1988, 87:250-254.

47. Sobhanian H, Razavizadeh R, Nanjo Y, Ehsanpour AA, Jazii FR, Motamed N, Komatsu S: Proteome analysis of soybean leaves, hypocotyls and roots under salt stress. Proteome Science 2010, 8:19-33.

48. Hayashi M, Takahashi H, Tamura K, Huang J, Yu LH, Kawai-Yamada M, Tezuka T, Uchimiya H: Enhanced dihydroflavonol-4-reductase activity and NAD homeostasis leading to cell death tolerance in transgenic rice. Proceedings of the National Academy of Sciences of the United States of America 2005, 102:7020-7025.

49. Xie DY, Jackson LA, Cooper JD, Ferreira D, Paiva NL: Molecular and biochemical analysis of two cDNA clones encoding dihydroflavonol-4reductase from Medicago truncatula. Plant physiology 2004, 134:979-994.

50. Dixon RA: Natural products and plant disease resistance. Nature 2001, 411:843-847

51. Tunc-Ozdemir M, Miller G, Song L, Kim J, Sodek A, Koussevitzky S, Misra AN, Mittler R, Shintani D: Thiamin confers enhanced tolerance to oxidative stress in Arabidopsis. Plant physiology 2009, 151:421-432.

52. Ahn IP, Kim S, Lee YH: Vitamin B1 functions as an activator of plant disease resistance. Plant physiology 2005, 138:1505-1515.

53. Ahn I, Kim S, Lee Y, Suh S: Vitamin B1-induced priming is dependent on hydrogen peroxide and the NPR1 gene in Arabidopsis. Plant physiology 2007, 143:838-848

54. Sayed S, Gadallah M: Effects of shoot and root application of thiamin on salt-stressed sunflower plants. Plant Growth Regulation 2002, 36:71-80.

55. Ahn I, Kim S, Lee Y: Vitamin B1 functions as an activator of plant disease resistance. Plant physiology 2005, 138:1505-1515.

56. Majumder A, Johnson M, Henry S: 1-myo-Inositol-1-phosphate synthase. Biochimica et Biophysica Acta (BBA)-Lipids and Lipid Metabolism 1997, 1348:245-256

57. Iabal M, Afzal A, Yaegashi S, Ruben E, Triwitayakorn K, Njiti V, Ahsan R, Wood A, Lightfoot D: A pyramid of loci for partial resistance to Fusarium solani f. sp. glycines maintains Myo-inositol-1-phosphate synthase expression in soybean roots. TAG Theoretical and Applied Genetics 2002, 105:1115-1123.

58. Donahue JL, Alford SR, Torabinejad J, Kerwin RE, Nourbakhsh A, Ray WK, Hernick M, Huang X, Lyons BM, Hein PP: The Arabidopsis thaliana myoinositol 1-phosphate synthase1 gene is required for myo-inositol synthesis and suppression of cell death. The Plant Cell 2010, 22:888-903.

59. Das-Chatterjee A, Goswami L, Maitra S, Dastidar KG, Ray S, Majumder AL: Introgression of a novel salt-tolerant L-myo-inositol 1-phosphate synthase from Porteresia coarctata (Roxb.) Tateoka (PcINO1) confers salt tolerance to evolutionary diverse organisms. FEBS letters 2006, 580:3980-3988

60. Majee M, Maitra S, Dastidar KG, Pattnaik S, Chatterjee A, Hait NC, Das KP, Majumder AL: A novel salt-tolerant L-myo-inositol-1-phosphate synthase from Porteresia coarctata (Roxb.) Tateoka, a halophytic wild rice. Journal of Biological Chemistry 2004, 279:28-39.

61. Gierl A, Frey M: Evolution of benzoxazinone biosynthesis and indole production in maize. Planta 2001, 213:493-498.

62. Macdonald H: Auxin perception and signal transduction. Physiologia Plantarum 1997, 100:423-430

63. SHARAF EF, FARRAG AA: Induced resistance in tomato plants by IAA against Fusarium oxysporum lycopersici. Polish Journal of Microbiology 2004, 53:111-116.

64. Sharma N, Rahman MH, Strelkov S, Thiagarajah M, Bansal VK, Kav NNV: Proteome-level changes in two Brassica napus lines exhibiting differential responses to the fungal pathogen Alternaria brassicae. Plant Science 2007, 172:95-110.

65. Gowri G, Bugos RC, Campbell WH, Maxwell CA, Dixon RA: Stress responses in alfalfa (Medicago sativa L.): X. Molecular cloning and expression of Sadenosyl-I-methionine: caffeic acid 3-O-methyltransferase, a key enzyme of lignin biosynthesis. Plant physiology 1991, 97:7-14.

66. Guo D, Chen F, Inoue K, Blount JW, Dixon RA: Downregulation of caffeic acid 3-O-methyltransferase and caffeoyl CoA 3-O-methyltransferase in 
transgenic alfalfa: impacts on lignin structure and implications for the biosynthesis of $\mathrm{G}$ and $\mathrm{S}$ lignin. The Plant Cell 2001, 13:73-88.

67. Sun S, Zhao J, Wu X, Guo N, Wang Y, Gai J, Xing H: Resistance of Soybean Germplasm to Phytohpthora in HuanhuaiValley. Soybean Science 2008, 27:465-470.

68. Burnham K, Dorrance A, Francis D, Fioritto R, Martin S: Rps8, a new locus in soybean for resistance to Phytophthora sojae. Crop science 2003, 43:101-105.

69. Natarajan S, Xu C, Caperna T, Garrett W: Comparison of protein solubilization methods suitable for proteomic analysis of soybean seed proteins. Analytical biochemistry 2005, 342:214-220.

70. Bradford M: A rapid and sensitive method for the quantitation of microgram quantities of protein utilizing the principle of protein-dye binding. Analytical biochemistry 1976, 72:248-254.

71. Yan J, Wait R, Berkelman T, Harry R, Westbrook J, Wheeler C, Dunn M: A modified silver staining protocol for visualization of proteins compatible with matrix-assisted laser desorption/ionization and electrospray ionization-mass spectrometry. Electrophoresis 2000, 21:3666-3672.

72. Gharahdaghi F, Weinberg C, Meagher D, Imai B, Mische S: Mass spectrometric identification of proteins from silver-stained polyacrylamide gel: a method for the removal of silver ions to enhance sensitivity. Electrophoresis 1999, 20:601-605.

doi:10.1186/1477-5956-9-52

Cite this article as: Zhang et al.: Proteomics study of changes in

soybean lines resistant and sensitive to Phytophthora sojae. Proteome

Science 2011 9:52.

\section{Submit your next manuscript to BioMed Central and take full advantage of:}

- Convenient online submission

- Thorough peer review

- No space constraints or color figure charges

- Immediate publication on acceptance

- Inclusion in PubMed, CAS, Scopus and Google Scholar

- Research which is freely available for redistribution

Submit your manuscript at www.biomedcentral.com/submit 